\title{
Algunas notas sobre los límites y márgenes de los estudios en Comunicación
}

\begin{abstract}
Álvaro CUADRA ROJAS*
\section{Introducción}

En los años recientes se ha venido instalando entre nosotros lo que se ha dado en llamar estudios en comunicación. La historia de este trayecto en América Latina, apenas comienza a escribirse $^{1}$. Desde hace ya varias décadas nos hemos visto invadidos por este tipo de estudios que bajo sellos diversos reclaman su legitimidad en el ámbito de las ciencias sociales. A decir verdad, hoy resulta una tarea ardua delimitar qué es lo propiamente comunicacional cuando el resto de las disciplinas de las ciencias sociales utilizan categorías, teorías y modelos nacidos de la reflexión en comunicaciones. Conviene recordar en este punto aquello que ya señalaba Baudrillard ${ }^{2}$ en cuanto a la defragmentación y desistematización del saber y, en este sentido, reconocer que lo comunicacional es un territorio emblemático de esta nueva condición de los saberes.

Una reflexión como la que nos proponemos en este artículo es, ante todo, necesaria, aunque estamos ciertos no es suficiente. Los estudios comunicacionales, sea bajo la etiqueta de la semiótica, los estudios culturales, la mediología, los estudios visuales, los estudios de medios y muchas otras, todos evidencian algunas tensiones en sus presupuestos que bien merecen una mirada más atenta.

Hemos tomado como punto de referencia una interesante discusión de los historiadores expuesta por Peter Burke ${ }^{3}$ en un libro reciente, pues algunos aspectos problemáticos de esta disciplina resultan pertinentes en el ámbito comunicacional. En efecto, Burke, a partir de un diagnóstico claro, la expansión del universo de los historiadores, desde la historia nacional a la historia local y universal, plantea lo que llama "una especie de crisis de identidad" "Para explicar el momento actual por el que atraviesa la disciplina de la historia, nos ofrece un resumen que opone la historia tradicional o rankeana -por el gran historiador alemán Leopold von Ranke (1795-1886) - a la nouvelle histoire. Así, la pretensión de estudiar los Estados y los grandes acontecimientos políticos y guerras se opone a la idea de "historia total", los mismo que la narración de acontecimientos contrasta con el reclamo de la nueva historia en cuanto a analizar estructuras. Otro aspecto destacado por Burke es el apego de los tradicionalistas a una "visión desde arriba" apegada a "documentos oficiales", mientras que la nueva historia apuesta más bien a una "visión desde abajo" y a la
\end{abstract}

\footnotetext{
* Académico Universidad ARCIS.

${ }^{1}$ La instalación de la Comunicación Social en América Latina, en tanto disciplina con pretensiones de autonomía y cientificidad, se produjo hacia los años '60 con la llegada de los modelos funcionalistas norteamericanos, de base sociológica o de la sicología conductista.

Sin embargo, al decir de Martín Barbero, dicha instalación asumió de entrada un carácter mucho más pragmático que teórico, de acuerdo al perfil administrativo que caracterizaba a esos modelos, para los cuales toda reflexión sobre fundamentos o fines aparecía como especulativa y por ende, inútil y todo conocimiento se validaba y legitimaba en su operatividad, al interior de un marco social tomado como dato. Y el contexto socio histórico global en que los estudios sobre comunicación hacen su aparición, es la problemática del desarrollo inaugurada en los años '50 desde la actividad de organismos e instituciones internacionales (entre las cuales, la CEPAL es fundamental para la región) hasta la preocupación activa del gobierno norteamericano y sus agencias de "ayuda al desarrollo", en especial después del triunfo de la Revolución Cubana en 1959.

Santa Cruz, Eduardo. 2005. Estudios de comunicación en América Latina y Chile: acerca de causas y azares. Manuscrito inédito.

${ }^{2}$ Jean Baudrillard. 2001. Cultura y simulacro. Editorial Kairós, (6º Edición). Barcelona.

${ }^{3}$ Peter Burke. 1999 (1991). Obertura: la nueva historia, su pasado y su futuro en Formas de hacer historia. Alianza Editorial. Madrid, pp. 11-38

${ }^{4}$ Op. Cit., p. 12
} 
inclusión de fuentes no tradicionales para el trabajo histórico (fuentes orales o visuales, por ejemplo). Por último, ambos paradigmas difieren en cuanto al tipo de preguntas que se puede plantear el historiador, y en este sentido, la nueva historia renuncia a la pretensión de "objetividad" y al trabajo circunscrito a los profesionales de la historia para abrirse al relativismo cultural de carácter más bien interdisciplinario.

Si bien se atribuye la nueva historia a los historiadores asociados a la revista Annales (1929): Lucien Febvre, Marc Bloch y luego a Fernand Braudel, lo cierto es que el enfoque no es tan nuevo como parece. Se encuentran afinidades a lo largo de la historia, desde Polibio en la antiguiedad a James Harvey Robinson (1912), pasando por varios historiadores del siglo XIX. Como concluye Burke: "Lo nuevo no es tanto su existencia cuanto el hecho de que quienes la practican sean ahora extremadamente numerosos y rechacen ser marginados" 5 .

El texto de Peter Burke posee la virtud de resumir a grandes rasgos las tensiones que atraviesa, hoy por hoy, la disciplina de la historia. Más allá, no obstante de su riqueza descriptiva, el texto despliega una potente "problematización" de categorías centrales para el pensamiento histórico contemporáneo.

En efecto, un problema central en las tesis de la nueva historia, en particular la pretensión de una historia total, es que cuanto más amplias son las categorías de análisis, tanto más complejas se tornan. Detectamos por lo menos cuatro categorías dignas de ser revisadas: Cultura, Cultura Popular, Cotidianización, Rutinización, sólo por mencionar las más recurrentes.

Si bien las nuevas tendencias poseen la virtud de ampliar el universo de lo cognoscible, no es menos cierto que esta expansión tiene un precio: la imprecisión. Ésta es casi inevitable si pensamos que la nueva historia se nutre de diversas disciplinas como la sociología, la economía, etcétera.

Otro punto importante es el énfasis en la llamada "cultura material", pues, en principio, como sostiene Burke, “...no hay ninguna buena razón para restringir los métodos arqueológicos a la prehistoria..." ". Pero, como nos previene el autor, no se puede negar que la cultura material bien pudiera utilizarse como mera confirmación de una hipótesis afincada en pruebas literarias.

Por último, se podría establecer una crítica a Burke en cuanto no considera un aspecto fundamental en la construcción del discurso histórico: los límites del imaginario y sus lenguajes. Entendemos que es una zona farragosa, pero pareciera que los procesos de construcción de conocimiento no son ajenos a la metaforización epistemológica como expresión última del imaginario social de una época y una cultura dadas.

Nuestra hipótesis apunta a que los estudios comunicacionales comparten las tensiones expuestas por Burke a propósito de la nueva historia. Por de pronto, los estudios comunicacionales han sido propuestos como análisis de una cultura. Tanto es así que la semiótica, una de las ramas emblemáticas de este tipo de estudios, llega a reclamarse como una teoría general de la cultura ${ }^{7} \mathrm{o}$, el caso de la teoría crítica -en particular las tesis de Jürgen Habermas ${ }^{8}$ - se propone como una teoría de la acción comunicativa para explicar la

\footnotetext{
${ }^{5}$ Op. Cit., p. 21

${ }^{6}$ Op. Cit., p. 29

${ }^{7}$ Umberto Eco. 1981. Tratado de semiótica general. Ed. Lumen, Barcelona. Véase p. 32 y ss.

${ }^{8}$ Habermas, Jürgen. 1989. Teoría de la Acción Comunicativa. Ed. Taurus, Buenos Aires. Para los efectos de nuestra exposición utilizamos fundamentalmente los interludios I y II. Interludio Primero: acción social actividad teleológica y comunicación, Tomo I, pp. 351-419. Interludio Segundo: sistema y mundo de la vida, Tomo II, pp. 161-261.
} 
sociedad como un todo. En síntesis, lo comunicacional, sea con un énfasis semiológico, sociológico, antropológico (mediología) o histórico intenta dar cuenta de un holos en que desaparece la distinción entre lo central y lo marginal. Este relativismo cultural totalizante intenta recuperar teóricamente determinados constructos socio-culturales bajo la forma de epistemes, regímenes de significación u otras categorías del mismo tenor.

El estudio de una cierta cultura total remite a un segundo rasgo de este tipo de investigaciones, si bien se reconocen y describen algunos acontecimientos, estos sólo poseen sentido en cuanto se inscriben en un gran modelo, lo que nos lleva a observar que los estudios comunicacionales enfatizan el análisis y construcción de estructuras sin atender, salvo como antecedente, a la narración de acontecimientos.

Un tercer aspecto, muy marcado en el ámbito latinoamericano, es la preeminencia de estudios comunicacionales que privilegian la "mirada desde abajo". Este énfasis aparece expuesto bajo la denominación de "cotidianeidad" que como nos recuerda Henri Lefebvre: "Lo cotidiano es lo humilde y lo sólido, lo que se da por supuesto, aquello cuyas partes y fragmentos se encadenan en un empleo del tiempo. Y esto sin que uno (el interesado) tenga que examinar las articulaciones de esas partes. Es lo que no lleva fecha. Es lo insignificante (aparentemente); ocupa y preocupa y, sin embargo, no tiene necesidad de ser dicho. Ética subyacente al empleo del tiempo, estética de la decoración del tiempo empleado. Lo que se une a la modernidad. Por ello hay que entender lo que lleva el signo de lo nuevo y de la novedad: el brillo, lo paradójico, marcado por la tecnicidad o por la mundanidad (...) Ahora bien, cada uno de ellos, lo cotidiano y lo moderno, marca y enmascara al otro, lo legitima y lo compensa",.

En efecto, un gran número de estudios comunicacionales se proponen como estudios de frontera de una cierta antropología cultural en que habla el hombre común, el lector de la época, la cultura popular. Nótese que este afán teórico posee un claro vector político, por una parte, y plantea no pocos problemas metodológicos, por otra.

Entre los problemas que plantea una orientación hacia lo popular o masivo destacan dos cuestiones, el tipo de fuentes y el carácter interdisciplinario de los estudios comunicacionales. Entre las prácticas más difundidas está el examen de fuentes alternativas, ya no el documento acreditado como tal por los historiadores sino textos visuales, periódicos o revistas de mayor o menor importancia, fotografías y otras fuentes de época. Este tipo de información es de suyo híbrida y compleja, posee la fuerza de aquello que se ha llamado "la cultura material". Sin embargo, al ser tan diversa reclama en cada caso métodos de análisis específicos no siempre bien resueltos. Es evidente, además, que un análisis híbrido como el que se postula obliga a una suerte de concubinato de varias disciplinas en aquello que llamamos estudios comunicacionales. En una palabra, los actuales estudios en comunicación son una suerte de mélange en que prima lo interdisciplinario, al punto de hacer indistinguibles las fronteras y matices entre las distintas disciplinas a las que se apela.

Las consecuencias de una mirada holística amplía el horizonte de comprensión de las diversas culturas objeto de estudio. No se puede negar que, efectivamente, las fuentes alternativas, enriquecen nuestra visión de la experiencia cotidiana de un momento histórico dado. Los estudios comunicacionales no sólo instalan nuevas interrogantes sino que han innovado sobre el carácter de dichas preguntas, poniendo de manifiesto continuidades y

Para una exposición histórica véase Axel Honneth. 1991. La Teoría Social Hoy, por Anthony Giddens \& J. Turner, Alianza Editorial, México, pp. 445-488.

${ }^{9}$ Henri Lefebvre. 1984. La vida cotidiana en el mundo moderno. Alianza Editorial, 3a . Edición, Madrid, pp. 36-37. Citado por: Carlos Ossandón y Eduardo Santa Cruz et al. 2005. El estallido de las formas. LOM Ediciones., Santiago. 
rupturas en el orden de la significación. Sin embargo, y al mismo tiempo, la mirada desde abajo nos lleva a reconstruir una heteroglosia que no siempre encuentra su síntesis.

Analizaremos en lo que sigue algunos aspectos que estimamos relevantes para los estudios comunicacionales, en estrecha relación con los problemas que plantean los estudios contemporáneos en las ciencias sociales y con la historia en particular. Con el propósito de dialogar con los estudios más actuales en nuestro medio, tomaremos como objeto de nuestra discusión el último libro publicado por los autores C. Ossandón y E. Santa Cruz: El estallido de las formas ${ }^{10}$.

Como ya nos advierte Ossandón en el prólogo del texto, desde fines del siglo XIX y las primeras décadas del siglo $\mathrm{XX}$ asistiríamos a "una importante transformación o reorganización cultural" " Dicha transformación resultaría de un alejamiento de los soportes del raciocinio político-ilustrado, propio de la segunda mitad del XIX, y la emergencia de nuevos soportes comunicacionales. Así por ejemplo, el género magazinesco propio de Sucesos (1902), Selecta (1909) o Pacífico Magazine (1913) darían buena cuenta de esta mutación. En un análisis más fino, el cambio radicaría en ciertos principios formales y lógicas de distribución de la información que están más allá de las autorías y de los estilos. Esta constatación atraviesa, en efecto, todo el estudio y da pie a una hipótesis de fondo que E. Santa Cruz enuncia de la siguiente manera: “...lo que hace la industria cultural es cotidianizar la modernidad”" En una línea próxima a aquella que expresara Renato Ortiz esta naturalización de la modernidad hace que los presupuestos del mundo nuevo que se avizora se tornen en sentido común para las masas. Esto explicaría, por ejemplo, cómo un orden oligárquico hizo que la vida cotidiana llegara a ser intolerable hacia los años veinte. Es interesante advertir cómo el texto enfatiza, justamente, la dimensión cultural de la modernidad, con todo cuanto ella posee de lenguaje. La modernidad no es sólo un proceso de transformación tecno económica sino una mutación del imaginario social que como afirma E.Santa Cruz, siguiendo a Ortiz y M. Berman, se expandió y se complejizó, alterando las categorías de tiempo y espacio, reconfigurando la "experiencia de la modernidad"13.

De particular interés, es la aproximación que propone Ossandón en "Zig- Zag o la imagen como gozo”. Al revisar la revista Zig-Zag (1905), nos previene sobre un desplazamiento desde lo puramente verbal hacia nuevas series visuales. Esta preeminencia de la imagen y de la composición hace de esta publicación algo para ser más bien visto que leído ${ }^{14}$. Ossandón nos recuerda que esta revista está en las antípodas de aquel axioma enunciado por Martí en cuanto a que "decirlo es verlo": en Zig- Zag es más bien la imagen fotográfica la que establece distancia y diferencia respecto de la serie lingüística. Al decir de Jacques Ranciere, en esta nueva relación entre lo decible y lo visible radicaría, justamente, la politicidad de las prácticas artísticas y por extensión, comunicacionales. Ossandón apunta en esa dirección e insinúa una mirada más amplia y abarcadora cuando señala: "No creemos que sea dicha ubicuidad /de la imagen/ la principal responsable del cambio de las pautas perceptivas contemporáneas, sino antes bien la generación de una condiciones o el despliegue de una posibilidades histórico culturales que vienen de más atrás y que son, a nuestro juicio, las que han permitido o están en la raíz del atributo divino” ${ }^{15}$.

\footnotetext{
${ }^{10}$ C. Ossandón y E. Santa Cruz. Op. Cit.

${ }^{11}$ Ibid.., p. 4

${ }^{12}$ Ibid., p. 18

${ }^{13}$ Ibid.., p. 30

${ }^{14}$ Ibid., p. 58

${ }^{15}$ Ibid.., p. 60
} 
No obstante una cierta radicalidad teórica en los hallazgos de la investigación, nos parece que estamos frente a una dialéctica inconclusa. En rigor, lo que Ossandón y Santa Cruz han descubierto es una transformación profunda de lo que llaman el imaginario social y que, en otros contextos pudiera llamarse la "conciencia burguesa"; una reconfiguración que se exterioriza como despliegues de superficies. Si en el arte el dispositivo collage y el ready made representó la nueva conciencia de las vanguardias, lo magazinesco es el dispositivo de la comunicación de masas que se hace cargo de la nueva concepción espacio temporal, fragmentaria, próxima a la experiencia psíquica y social. En pocas palabras, una lectura posible de este libro, insinuada aquí y allá por sus autores, es que el estallido de las formas entraña nuevas formas del imaginario, es decir: el estallido de las formas no es sino el nivel significante de un cambio en el régimen de significación, tanto en su dimensión económico cultural como en el modo de significación tanto a nivel de conceptos como de perceptos.

Es claro que una caracterización como la que se insinúa en el texto reclama unas operaciones que escapan a las pretensiones del escrito. En este sentido, pareciera que la extensa obra de Ossandón y Santa Cruz ha sido el dificultoso e imprescindible trabajo de campo, para arribar a la pregunta de orden filosófico cultural sobre la mutación de la conciencia burguesa en el Chile de fines del siglo XIX hasta la segunda década del siglo XX. El espacio periodístico chileno sufre un cambio importante en los primeros años del siglo XX. Ossandón es rotundo a este respecto: “...la prensa cambia su carácter" "16. Para nuestro autor, la cuestión radica en un nuevo sistema que construye artefactos y "significaciones" propias, en este sentido los lenguajes habrían adquirido una relativa autonomía. Ya no estaríamos ante superficies en las que se proyectan solamente fuerzas sociales o políticas sino que estaríamos frente a mutaciones en el orden simbólico: “...las publicaciones periodísticas que marcan este periodo instalan todo un juego de lenguajes y secciones, de saberes y géneros, que las transforman en una instancias de enunciación cuya articulación tiene que ver más con dimensiones estratégicas o comunicacionales que con autorías, rúbricas individuales o "desvíos subjetivos" $"$. En este punto caben dos advertencias, primero, la tesis implícita de una relativa autonomía de los lenguajes hacia fines del siglo XIX ha sido consignada por varios autores, entre ellos Jameson; segundo, se advierte un distanciamiento de la tesis de Foucault en cuanto a que si bien se reconoce un cambio en el carácter de la prensa, "...no habría que remedar en este punto el esquema de colapso y creación de 'epistemes' de Las palabras y las cosas de Michel Foucault",

Muchos de los hallazgos de Ossandón se inducen del examen de El Diario Ilustrado, cuestión que debilita en cierta forma algunas afirmaciones de carácter general. En cambio, Eduardo Santa Cruz procede a una mirada de conjunto del campo periodístico del período que contextualiza muchos de los asertos de Ossandón. Cuando E. Santa Cruz nos narra la emergencia del "modelo informativo" mediante la irrupción de El Mercurio de Santiago (1900) y de cómo el crecimiento de un mercado informativo y cultural de tipo moderno determinó la aparición de géneros, estilos y técnicas periodísticas específicas, entendemos cómo una cierta economía cultural, un modo de producir, distribuir y consumir bienes simbólicos, modificó un régimen de significación. Conviene aquí tener presente la expansión capitalista y la subsiguiente división del trabajo, de la cual ni el periodista ni el poeta serán

\footnotetext{
${ }^{16}$ Ibid, p. 155

${ }^{17}$ Loc. Cit.

${ }^{18}$ Loc. Cit.
} 
ajenos, pues como señala Ángel Rama ${ }^{19}$ : "Si dentro del modernismo el poeta comienza su toma de contacto más austera con la realidad, es en buena parte debido a que el nuevo sistema económico generaba una relación con ella mucho más estrecha y lo fuerza a su utilización rigurosa, como en general fuerza a los distintos estratos de la sociedad a una cuidadosa y racional utilización de los materiales fabricados por el hombre (desde los utensilios de mesa hasta los ferrocarriles) tendiendo, simultáneamente, a desacreditar los elementos naturales. El aprovechamiento de los recursos que brinda la naturaleza postula una servidumbre cada vez mayor del hombre que se inicia en el régimen de prestaciones de la sociedad actual. El poeta modernista no será una excepción dentro de este proceso general".

Destaquemos que E. Santa Cruz caracteriza el periodo como una transición hacia el periodismo liberal moderno, esto es, el abandono del periodismo ligado a la vocería y difusión de doctrinas a otro más próximo al emergente mercado informativo. Nuestro autor establece al pasar una relación que nos parece crucial: “...la relación entre la democratización y masificación de la noticia con la democratización política. El fundamento de esa actividad mediadora es la existencia autónoma y objetiva de la noticia, portadora de su propia verdad" 20 .

Entre los supuestos centrales en los que descansa toda la investigación realizada por Ossandón y Santa Cruz apunta hacia ciertos principios formales y lógicas de distribución de la información que están más allá de autorías o estilos, cuya forma arquetípico resultaría ser el magazine. Esta mutación de las superficies significantes entrañaría un cambio histórico según el cual la industria cultural cotidianiza la modernidad. Por de pronto, emergen dos cuestiones problemáticas, por una parte la idea de hay una historicidad inmanente a la forma, a los significantes; y por otra, las nociones de cotidianeidad como experiencia de una categoría histórico-social, a saber: la modernidad. Nos ocuparemos de manera ordenada de estas dos cuestiones, pues, a nuestro entender son de distinta índole.

\section{La cultura material: historia y forma}

El interés por la materialidad de la cultura ha sido el reclamo de muchos estudiosos casi como una reacción al análisis simbólico que reinó en las décadas precedentes, en particular las investigaciones de la semiología ligada al estructuralismo ${ }^{21} \mathrm{y}$, anteriormente, el llamado análisis de discurso, todos con la pretensión de develar matrices semánticas latentes en las diversas textualidades. Así por ejemplo, Alain Ranaud lo plantea sin ambages: "A una tradicional y sin duda limitada, si no caduca, aproximación metafísica de lo Imaginario, siempre más o menos postulada implícitamente como una facultad, una "naturaleza" -la Imaginación- separada de sus condiciones técnico-materiales de producción y de funcionamiento, convendría, por tanto, oponer polémicamente el punto de vista de una antropología cultural de las superficies capaz de rendir cuentas de las mediaciones visuales, al mismo tiempo técnicas, semánticas y estéticas que organizan (especular y especulativamente) la producción y la reproducción de los Sujetos humanos concretos de una Cultura especial; de esta manera se podría hablar de algo así como, por ejemplo, el "Hombre-Cuadro", o el "Hombre-Cliché", o también del "Hombre-Pantalla" (de forma

\footnotetext{
19 Ángel Rama. 1995. Rubén Darío y el Modernismo, España, Alfadil Ediciones, Colección Trópicos, pp. 5-18; 3579.

${ }^{21}$ Conviene hacer notar que entre los estructuralistas, uno de los más preclaros por su intuición perspicaz fue Roland Barthes quien ya en 1956 en Mythologies se pregunta por las posibilidades de una "ideología de la forma" Roland Barthes. 1957. Mythologies. E. du Seuil. Paris.
} 
parecida a como McLuhan hablaba de "Hombre tipográfico"): por ello, bajo la unidad de esta misma noción - el "Hombre"-estaríamos obligados a tomar profundas diferencias de identidad internas y externas entre reales humanos que se completan según procedimientos ópticos / iconográficos radicalmente diferentes" ${ }^{, 22}$.

Entre las muchas discusiones que se dan en la disciplina de la historia, un lugar central lo ocupa el problema del "determinismo geográfico", esta categoría mutatis mutandis se relaciona, en parte, con el problema de la materialidad de la cultura. En un Coloquio de homenaje a Fernand Braudel ${ }^{23}$ se abordó el tema desde una perspectiva que bien nos pudiera interesar a la hora de pensar la cultura material. A este respecto, de manera especial, la polémica entre Braudel y Etienne Juillard es muy esclarecedora. En efecto, éste afirma que “...el significado de los datos espaciales (geográficos) cambia en función de todo un arsenal de otros factores tecnológicos, económicos, sociales y en consecuencia no puede decirse que haya un determinismo del espacio. Hay una componente espacial de un complejo de factores, y este componente espacial no está fijo, no está dado de una vez por todas" "24; a lo cual el maestro contesta, a propósito de la función del Ródano a través de la historia: " $E l$ determinismo es que un cierto número de causas arrastra un cierto número de consecuencias... La historia de Francia se ha desarrollado en un cierto espacio. No me gusta la palabra Hexágono, pero el hexágono está allî,"25.

Esta querella posee antecedentes en la escuela de los Annales. De hecho, Braudel sostiene que algunos historiadores "desespacializan" la historia, en este sentido, explica, que desea devolver a la geografía sus derechos "se llame o no determinismo"26. Braudel agrega que: "Lucien Febvre en 'La tierra y la evolución humana', no ha llegado hasta la negación pura y simple del espacio. El "posibilismo" de Lucien Febvre es un determinismo endulzado, pero todavía es un determinismo". Juillard, a su vez, escribe: "/El aporte del geógrafo/ Se funda no en un espacio abstracto y tampoco sobre un espacio dado de una vez. por todas, sino sobre el análisis de las estructuras funcionales de este espacio y de las interrelaciones que se desarrollan entre sus partes a medida que evolucionan los contextos tecnológicos, económicos, políticos y sociales",27.

La discusión nos interesa en cuanto pudiera iluminar la relación entre la materialidad de los soportes y los formatos que permiten la transmisión en un determinado espacio cultural y sus relaciones con determinados contextos. ¿De qué modo se relaciona una determinada forma y un contexto tecnológico, histórico, social y cultural determinado? ¿Existe una historicidad inmanente a la forma? Una pregunta que se plantea E. Santa Cruz en los siguientes términos: “¿Cómo se vinculó el "estallido de formas” que presencia el período con sentidos comunes en vías de masificación y diversificación?"28.

\footnotetext{
22 Alain Renaud. 1996. Comprender la imagen hoy. Nuevas imágenes, nuevo régimen de lo visible, nuevo Imaginario. En Videoculturas de fin de siglo.Cátedra, Madrid, pp. 11-26.

${ }^{23}$ El Centro de Encuentros de Châteauvallon, organizó el 18,19, 20 de octubre de 1985 las Jornadas Fernand Braudel. En este contexto, la tercera jornada estuvo dedicada a la historia de Francia. Durante esta discusión estuvieron presentes los profesores: Albert Du Roy, Francia, colaborador de Antena 2; Jean Guilaine, Francia, director de investigación en el CNRS; Etienne Juillard, Francia, discípulo de Bloch y Febvre; Karl Ferdinand Werner, Alemania, profesor de Edad Media; Claude Raffestin, Suiza, profesor de geografía; Emmanuel Le Roy Ladurie, Francia, profesor del Collège de France y Théodore Zeldin, historiador de Inglaterra. Las ponencias y discusiones han sido recogidas en un interesante libro: Braudel, Fernand. 1996. Una lección de historia. Fondo de Cultura Económica. México, pp. 196-274

${ }^{24}$ Ibid.., p. 256

${ }^{25}$ Ibid.., p. 257 y 261

${ }^{26}$ Ibid.., p. 255

${ }^{27}$ Ibid.., p. 224

${ }^{28}$ Ibid., p. 21
} 
Siguiendo el pensamiento de Juillard, podríamos avanzar que la forma adquiere un cierto valor semántico, esto es, se historiza, sólo en cuanto se transforma en una estructura funcional, entrando en relación con determinados contextos tecnológicos, económicos, políticos y sociales. Toda innovación significante, como el collage o el magazine, exterioriza una matriz que entraña un cambio cualitativo. El collage, por ejemplo, supone la temporalización del espacio, la fragmentación de lo visual en un mosaico en que lo que cuenta es la simultaneidad, lo cinético, lo ubicuo. Este estallido de lo representacional sólo es concebible en un cierto despliegue de superficies, sin embargo, tal despliegue formal adquiere un sentido en ciertos contextos acotados En breve, el collage y la imaginería surrealista son concebibles como formas arquetípicas del arte en un momento de modernidad del siglo XX en occidente y no, por ejemplo, en El jardín de las delicias de Bosch ${ }^{29}$.

La forma expresa una mirada en que las visiones de mundo se escinden para siempre, ya no será una totalidad coherente, ahora será el collage, lo caleidoscópico, aquello que adquiere primacía en la conciencia de los artistas como verdaderas metáforas de un nuevo imaginario: el arte deviene montaje. Esta disociación temporo-espacial encuentra su correlato en ese gran montaje de vidas y arquitecturas, masas y rascacielos: la urbe del siglo $X X$. Bastará recordar títulos como Berlin Alexanderplatz de Döblins o aquella novela desgarradora de Dos Passos Manhattan Transfer. Nueva York es el espacio donde se yuxtaponen vidas y aconteceres, nueva Babilonia de los tiempos modernos; Manhattan Transfer inaugura una escritura y una sintaxis narrativa que elide la conexión causal. La ciudad es el espacio geométrico que imaginará Mondrian años más tarde, el escenario de vidas fragmentarias.

Ahora bien, el magazine se desarrolla como forma prototípica de la naciente industria cultural, adscrita no obstante a la misma matriz del collage. La matriz a la que aludimos no es sino una profunda mutación en la percepción y significación del espacio y el tiempo. A la continuidad se opone la discontinuidad, a la linealidad cronológica se opone la simultaneidad, el salto o corte. A la referencialidad naïf se opone la significación, la matriz lecto-escritural se ve alterada por nuevas coordenadas. En este estricto sentido, se entiende la descripción que ofrece Ossandón cuando escribe: "En un plano más específico, dicha transformación cultural se expresa en el imperio de nuevas visibilidades o exterioridades sígnicas, en inéditas relaciones entre letra e imagen, y en la estimulación de unas sensibilidades que ya no tienen como fuente la cultura ilustrada-letrada. Esta nueva configuración da específicamente cuenta de unos formatos que tienden parcialmente a reemplazar el juicio por la inclinación, el raciocinio por la vista, el autor por el orden de los signos, lo irrepetible por lo repetible, el aura por la serie" ${ }^{30}$. A su vez, el público más amplio y diversificado que se constituye da cuenta también de conexiones culturales de distinto tipo y de distintas y cambiantes estrategias de recepción; público que expresa nuevos gestos (más ligados al (h)ojear que al focalizar) y ritmos (más extensivos que intensivos) de lectura",31

\footnotetext{
${ }^{29}$ La nueva poesía intenta espacializar el texto poético del mismo modo como la pintura cubista quiere temporalizar el espacio pictórico. El texto poético vanguardista deviene, de este modo, una suerte de hipertexto a los que hoy estamos tan familiarizados: diposición no líneal ni secuencial de la información que pone en relación signos verbales y no verbales: un collage. El collage fue concomitante con otras técnicas coevas como el cut up o el assemblage que se generan de manera independiente en el mundo anglosajón; Ulises de Joyce o Manhattan Transfer de John Dos Passos dan buena cuenta de ello. En la narrativa latinoamericana será Rayuela (1963) de Julio Cortázar la obra que aclimatará el collage en nuestra novela.

${ }^{30}$ Walter Benjamín. 1989. La obra de arte en la época de su reproducibilidad técnica, en Discursos Interrumpidos I. Taurus, Argentina.

${ }^{31}$ C. Ossandon y E. Santa Cruz. Op. Cit., p. 11
} 
Las nuevas relaciones sígnicas, particularmente las relaciones entre las series visuales linguiísticas y no-lingüísticas tenderían a reemplazar el raciocinio por la vista. Estaríamos ante el advenimiento de aquello que Sartori, en un contexto televisivo ha llamado el homo videns. Por decirlo de otro modo, la ciudad letrada evidenciaría tempranamente sus primeras arrugas. Pareciera que el estallido de las formas responde a la incrustación de ciertas estructuras funcionales que entran en relación con contextos específicos. Una observación, de carácter deontológico si se quiere, es entender la materialidad de la cultura (el plano significante) no sólo en su "materialidad" sino, y principalmente, en las conexiones que esto suscita en la red de relaciones con los diversos contextos en que emerge. La materialidad de la cultura no son los objetos materiales ni siquiera la materialidad de los signos. Utilizando una dicotomía mediológica habría que decir que no se trata tan sólo de la materia organizada sino, además, de la organización materializada ${ }^{32}$. Esta suma de ciertas estructuras funcionales y de la red de relaciones contextuales, a comienzos del siglo XX, es lo que podríamos llamar desde una perspectiva comunicacional, en algún sentido, modernidad.

Esta aclaración es imprescindible para comprender los límites de la hipótesis propuesta en El estallido de las formas. La hipótesis es que lo que hace la industria cultural es precisamente cotidianizar ${ }^{33}$ la modernidad, es decir, naturalizarla. Da sentido a esa experiencia ordinaria de vivir la vida, en las claves civilizatorias modernas.

En esa perspectiva, lo que interesa es analizar de qué manera la presencia de ciertos factores modernizadores de carácter estructural ${ }^{34}$, tales como el crecimiento económico, el desarrollo urbano, la expansión de las comunicaciones y el transporte, las nuevas tecnologías, la industrialización, el desarrollo del aparato educacional, etc. se vivieron a nivel del sentido común en las primeras décadas del siglo XX en nuestro país, configurando un cierto imaginario social en el espacio de la vida cotidiana. En este período se manifestaría, a la vez, lo que los autores citados llaman un escenario propicio -en términos discursivos y eventualmente prácticos- al cambio como fuerza motriz, simultánea a la sensación de crisis, desigualdad, injusticias sociales extremas, pérdida de rumbo histórico, etc. Se manifestaría igualmente la necesidad de ampliar las posibilidades y oportunidades de acceder a los beneficios de la nueva modernidad"35. En la hipótesis de E. Santa Cruz se hace nítida la presencia de "factores modernizadores" cuya síntesis se encontraría en un cierto "imaginario social" secularizado como "sentido común" en la experiencia de lo cotidiano en que la mediación discursiva prototípica estaría dada por el formato magazine.

Con todo lo lúcida que aparece a primera vista, la hipótesis no está exenta de riesgos, pues si bien vincula "el estallido de las formas" a la masificación de cierto imaginario propio de la modernidad en el Chile de principios de siglo, supone un papel central a los medios y formatos como instancias de construcción del imaginario. La relación entre los dispositivos técnicos y las instituciones vigentes pareciera más compleja, de tal manera que el "sentido común" se arraiga tanto en la tradición (política, religiosa, social) como en la irrupción de lo nuevo.

Una segunda observación a la hipótesis tiene relación con el aspecto cronológico: admitiendo que la prensa cambia su carácter y que se reconfigura a la luz de nuevas modalidades y formatos en las primeras décadas del siglo XX, no es evidente que en el lapso de tan corto periodo el impacto de estos nuevos discursos hayan generado escenarios

\footnotetext{
${ }^{32}$ Regis Debray. 2001. Introducción a la mediología. Paidós, Barcelona, p. 30

${ }_{33}$ Cotidianización, Veralltäglichung, es el término acuñado por Weber en el sentido de Rutinización.

${ }^{34}$ En el sentido ocupado en Sofía Correa et al. 2001. Historia del siglo XX chileno. Editorial Sudamericana, Santiago.

${ }^{35}$ C. Ossandón y E. Santa Cruz. Op. Cit. , p. 23
} 
propicios al cambio, a la sensación de crisis o a una particular sensibilidad frente a las desigualdades. No negamos la vinculación necesaria, mas no suficiente, entre la expansión de nuevos modos de significación y los avatares histórico sociales, sino que entendemos que dicha relación se da en plazos más extensos.

En este sentido, la historicidad inmanente a las formas puede advertirse en periodizaciones más largas. Un régimen de significación entraña siempre innovación y memoria, modernidad y tradición si se quiere; en rigor, las mutaciones se producen cuando lo nuevo deja de serlo. Esta tensión se ha acelerado en virtud de la compresión espacio temporal de la era contemporánea, pero resulta difícil de ser concebida a principios del siglo $\mathrm{XX}$.

Un tercer aspecto de la hipótesis que remite la experiencia de la modernidad a lo cotidiano, por su complejidad bien merece un comentario aparte.

\section{Narración o estructura: lo cotidiano}

Es interesante notar que en los estudios comunicacionales de corte historiográfico se dan cita dos temporalidades distintas que cohabitan la descripción de lo cotidiano. Por una parte, está la descripción del texto - ocurrencia, el periódico o la revista datada, una suerte de historia événementielle circunscrita a una época determinada; por otra parte, empero, en este tipo de estudio se aspira a inscribir el discurso-acontecimiento en una estructura de longue durée. Esto es, un cierto régimen de significación, frente al cual tal o cual discurso adquiere su valor en tanto acontecimiento discursivo.

La descripción de textos no remite, por cierto, a la descripción de funciones de un sujeto o narrador sino que se refiere más bien al plano formal o de superficie. Como señala Ossandón: "No deja de ser revelador que, en el lapso que va de mediados del siglo XIX a las primeras décadas del siglo XX, en Chile, la mirada tiende a deslizarse casi 'naturalmente' de la descripción de determinadas funciones y lugares de unos sujetos que, como nos recuerda Michel Foucault, no están fuera del campo discursivo, al examen de unos formatos periodísticos que exhiben distintas relaciones, géneros, secciones y juegos de lenguaje"36. Estos formatos no serían ajenos, insistamos, al decurso histórico, por el contrario, ellos mismos son acontecimientos discursivos y darían cuenta de ciertos contextos y condiciones, el Estado, los avatares políticos y el mercado de bienes simbólicos. La historicidad, en rigor, no es un atributo inmanente a la forma sino que emana de la situación concreta frente a determinados contextos, es más una relación entre una estructura funcional y una estructura lógica formal.

Las formas, el plano significante o de superficie, adquiere una dimensión semántica en cuanto entra en relación con un contexto social, histórico, tecnológico, en que dicha forma adquiere una determinada significación. El magazine, de suyo, una arquitectura meramente formal, adquiere significado y "sentido" sólo en cuanto cristaliza lo que podríamos llamar, con todas las reservas del caso, una nueva conciencia, un complejo psíquico, social, experiencial cuya expresión se da en lo cotidiano.

Se ha dicho que uno de los eslabones débiles de los llamados Cultural Studies ${ }^{37}$, ha sido el énfasis en lo cotidiano en cuanto inmediatez experiencial psíquica y social de los fenómenos culturales. El término "cotidiano" no es, en absoluto, transparente. De hecho, lo cotidiano funde en sí la experiencia ordinaria del "hombre común", la vida diaria y se opone

\footnotetext{
${ }^{36}$ Ibid., p. 247

${ }^{37}$ Para una exposición panorámica de los Estudios Culturales, véase Armand Mattelart y Eric Neveau.2004. Introducción a los estudios culturales. Paidós. Barcelona.
} 
a las abstracciones como "sociedad" y "cultura" e, incluso, deja de lado "los grandes sucesos de la historia". En rigor, sociedad y cultura se funden y, por momentos, se confunden. Como señala Burke: "En lo cotidiano entran acciones -Braudel lo define como el reino de la rutina- y también actitudes que podríamos llamar hábitos mentales. Podría incluir hasta lo ritual. Lo ritual, un hito de las ocasiones especiales en la vida de los individuos y comunidades, se define a menudo por oposición a lo cotidiano. . . Visto desde dentro lo cotidiano parece intemporal $" 38$.

Esta crítica olvida el hecho de que la cotidianeidad que se reclama es siempre experiencia de algo y que ese algo está ligado de manera directa o indirecta con un proceso objetivo, un principio de estructuración si se quiere, de reconfiguración simbólica, como es el caso de la mediatización. De tal suerte que los estudios de campo en esta línea constituyen la mediación entre una experiencia cotidiana (perceptual y cognitiva) y un proceso que se inscribe en las transformaciones de un régimen de significación, esta mediación es tanto epistemológica como política.

Así se entiende en toda su profundidad la tesis que subyace en todos los capítulos de este libro en el sentido de que la modernidad se naturaliza en la vida cotidiana por la vía de los diversos dispositivos que exhiben los medios de comunicación en una época dada o como afirma E. Santa Cruz: “...lo que hace la industria cultural es cotidianizar la modernidad..." 39 . Esta manera de leer este texto vuelve comprensible la operación que propone Ossandón, el tránsito desde determinados acontecimientos discursivos exhibidos en algunos soportes de la prensa periódica y ciertos sujetos enunciativos que modifican sus relaciones con la política, el Estado o el mercado de los bienes simbólicos. No obstante, se produce un décalage temporo -espacial, pues se quiere fundir dos ámbitos con vectores temporales difíciles de conciliar: la inmediatez de la experiencia cotidiana con cambios de largo plazo en un régimen de significación.

\section{Masas, prensa y democracia}

No es el caso discutir aquí la relación entre lo comunicacional y lo político. Digamos, por lo menos, que dicha relación pareciera mucho más compleja que la que han imaginado los estudios comunicacionales y muchos pensadores políticos. Tomemos, a modo de ejemplo, la correlación que se establece entre cobertura mediática y eficacia política. Se tiende a creer que a mayor cobertura mayor éxito de un discurso, cuestión que puede ser refutada empíricamente. Pareciera que en el universo simbólico todo opera como una estructura funcional que no admite determinismos mecánicos. Esta complejidad, precisamente, nos lleva a problematizar una presunta relación entre democratización política y democratización de la noticia, como proponen nuestros autores: “...la relación entre la democratización y masificación de la noticia con la democratización política. El fundamento de esa actividad medidora es la existencia autónoma y objetiva de la noticia, portadora de su propia verdad"40.

$\mathrm{Al}$ afirmar que se democratiza y se masifica la noticia se quiere significar que en un momento dado de nuestra historia, en rigor un momento económico -cultural, las condiciones de producción, distribución y consumo de bienes simbólicos hace posible masificar la información. Ahora bien, colegir de lo anterior la democratización política entraña un riesgo, pues bien mirado lo político como ámbito privilegiado de la legitimidad y

\footnotetext{
${ }^{38}$ P. Burke. Op. Cit., p. 26

${ }^{39}$ C. Ossandón y E. Santa Cruz. Op. Cit., p. 23.

${ }^{40}$ Ibid., p. 121
} 
administración del poder, diverge del dominio propiamente simbólico. Recordemos, la relación entre política y medios, la administración de los medios y la propaganda política adquirieron su fisonomía plenamente modernas en la Alemania de Hitler ${ }^{41}$.

En pocas palabras, cultura y política representan dos vectores, en principio distintos. Reconozcamos, sin embargo, que la tesis es cautivante. ¿De qué modo la masificación de la información a través de nuevos soportes y formatos puede democratizar una sociedad?

En una primera aproximación, podríamos afirmar que el desarrollo de determinadas tecnologías, incluidos los nuevos formatos periodísticos, los desarrollos en impresión y fotografía, permitieron la prensa de gran tiraje y la irrupción de voces nuevas. Aparece, en efecto, el diario gremial, la prensa obrera, en fin, se extienden las voces posibles. La producción, ligada a los desarrollos tecnológicos, la distribución ligada a los medios de transporte y de comunicaciones, y el consumo ligado a la creciente alfabetización configuran una nueva economía cultural que no democratiza, pero facilita el proceso democratizador.

En una segunda aproximación, habría que introducir una sutileza: la masificación de los medios -junto a las políticas educacionales- permite la incorporación paulatina de nuevos públicos. Estos públicos expuestos -por lapsos prolongados- a nuevos estímulos perceptuales y cognitivos van sedimentando un nuevo sensorium, una nueva matriz cognitiva, es decir: un nuevo modo de significación. Este nuevo modo de significación al ser contrastado con los contextos sociales, culturales, económicos y políticos, se instala, paulatinamente, como norma o sentido común.

En suma, pareciera que los estudios comunicacionales se instalan en una zona de luces y sombras. Su aporte es indudable pues pone de relieve tópicos pocas veces advertidos por historiadores u otros estudiosos. Por su naturaleza híbrida e interdisciplinaria, presentan límites difusos, tanto a nivel de sus definiciones, como en las fuentes e incluso en los métodos que se utilizan. En un momento en que las ciencias sociales están siendo revisadas desde sus fundamentos, es importante que los estudios comunicacionales vuelvan sobre sus pasos para preguntarse sobre sus propios límites y posibilidades.

\footnotetext{
${ }^{41}$ Se admiten a lo menos tres hitos de la modernidad que confluyen en la espectacularización de lo real. La estética negativa de las vanguardias, la llamada estética del shock del dadaísmo, en particular; la construcción de una segunda naturaleza técnica - una racionalidad productivista - según los presupuestos expresionistas y de la Bauhaus hasta Le Corbusier y el tercer hito lo constituye, precisamente, el nacionalsocialismo: “...lo nuevo, en la teoría programática de los medios de comunicación esbozada por Goebbels, residía más bien en el proyecto global de una nueva cultura política, organizada a través de los medios técnicos de comunicación más adelantados de la época, o sea, la radio y el cine, como una gran obra de arte total". Eduardo Subirats. 2001. Culturas virtuales. Editorial Biblioteca Nueva. Madrid., pp. 11 y ss.
} 